\title{
Repository Platform for Motivating Education
}

\author{
Timm Caporale ${ }^{1}$, Murat Citak ${ }^{2}$, Jonas Lehner ${ }^{3}$, Andreas Oberweis ${ }^{4}$, Andreas Schoknecht ${ }^{5}$, Meike Ullrich ${ }^{6}$ \\ ${ }^{1-6}$ Karlsruhe Institute of Technology, Institute AIFB, KIT-Campus Süd, 76128 Karlsruhe, Germany, \\ first_name.surname@kit.edu
}

Keywords

Course design, Didactic methods, Study motivation, Lecture modeling, Lecture repository.

\section{EXTENDED ABSTRACT}

Despite market demand, there is a lack of university graduates, especially in Information Systems (IS) (Granger et al., 2007). To attract both prospective and first-year students to pursue an academic education, universities have to provide a motivating study environment. A recent study reports a dropout rate of $35 \%$ for German university Bachelor programs and identifies lack of motivation as one of the main reasons (Heublein et al., 2010). To investigate the effect of showing the practical relevance of theoretical knowledge to students we provided a one-day lab with a fictitious but realistic use-case at Karlsruhe Institute of Technology (Caporale et al., 2013a). The general lab setting focused on Business Process Management (BPM) and students got the objective to model and improve the business processes of a fictitious company. As the evaluation of the lab showed, many students perceived the lab as a factor contributing to a better understanding of the connection between practical and theoretical aspects of BPM. To extend the lab we propose an integrated teaching concept which does not only consider theoretical foundations as defined in the curriculum (Learn), but also embraces the fields of science (Research) and professional practice (Apply) (Caporale et al., 2013b). To this avail, the fictitious company setting was developed further to provide a generic framework to derive appropriate use cases in order to enable a problem-oriented and holistic learning approach. This way, students directly experience the relevance and applicability of theoretical knowledge which in turn raises motivation.

The paradigm shift towards student-centered learning documented in the trend report prepared for the UNESCO 2009 World Conference on Higher Education by Altbach et al. (2009) emphasizes the need to involve students actively in the learning process. According to the authors, there is a trend towards imparting functional knowledge (e.g. the knowledge how to apply theory to practical situations) rather than solely teaching declarative knowledge which has to be memorized and regurgitated. This philosophy is exactly in line with our concept.

We are currently developing a platform to support the modeling and instantiation of modern university courses according to our concept. Essential part of this platform is a repository layer, which includes three main repositories: (i) a service repository, which offers functionality for collaboration and communication between participants as well as other course-supporting software like document management; (ii) a course administration repository, which provides general course management tools like course evaluation and user subscriptions and (iii) a didactic repository, which is the most important part as it contains didactical and methodical components as well as an examination toolbox, the fictitious company and the learning content itself. The four components (method, exam, learning content and use case) can be combined to learning items which are also stored in the didactic repository.

Above the repository layer, there is the course layer that contains the course modeler. With the help of the course modeler, lecturers can combine and orchestrate the desired repository elements from the repository layer to generate a course instance. Based on the platform integration, the selected elements can be evaluated during each instantiation to allow cyclic and continuous improvement.

As technical foundation the platform has a data layer, which consists of a database and a file server. Additionally a platform administration layer includes access control, user management and repository management features. 


\section{REFERENCES}

Altbach, P. G., Reisberg, L., and Rumbley, L.E. (2009). Trends in global higher education: Tracking an academic revolution: A report prepared for the UNESCO 2009 World Conference on Higher Education. Paris, France: UNESCO Division of Higher Education.

Caporale, T., Citak, M., Lehner, J., Schoknecht, A., and Ullrich, M. (2013a). Social BPM Lab: Characterization of a collaborative approach for Business Process Management education. Workshop on Social Business Process Management (SBM 2013). Vienna, Austria (accepted paper to appear).

Caporale, T., Citak, M., Lehner, J., Oberweis, A., Schoknecht, A., and Ullrich, M. (2013b). Motivating Course Conzept: Using active labs for BPM education. 21st European Conference on Information Systems (ECIS 2013). Utrecht, Netherlands (accepted paper to appear).

Granger, M., Dick, G., Jacobson, C. M., and Van Slyke, C. (2007). Information Systems Enrollments: Challenges and Strategies. Journal of Information Systems Education, 18(3), p. 303-311.

Heublein, U., Hutzsch, C., Schreiber, J., Sommer, D., and Besuch, G. (2010). Ursachen des Studienabbruchs in Bachelor- und in herkömmlichen Studiengängen: Ergebnisse einer bundesweiten Befragung von Exmatrikulierten des Studienjahres 2007/08. Hanover, Germany: HIS GmbH.

\section{AUTHORS' BIOGRAPHIES}

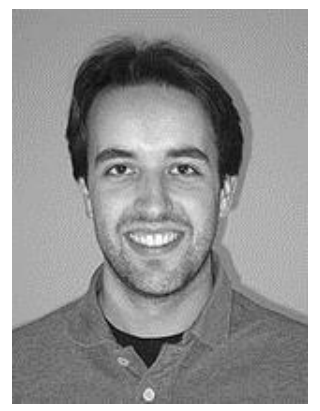

Timm Caporale graduated in business engineering from Karlsruhe Institute of Technology (KIT). Currently he is a research associate at the Business Information Systems chair of the Institute of Applied Informatics and Formal Description Methods (AIFB). His research areas are integrated campus information management and research-based education.

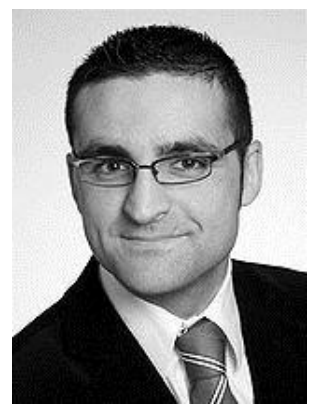

Murat Citak graduated in computer science from Karlsruhe Institute of Technology (KIT). Currently he is a research associate at the Business Information Systems Chair of the Institute of Applied Informatics and Formal Description Methods (AIFB). His research topics are Software-Engineering and Business Process Management.

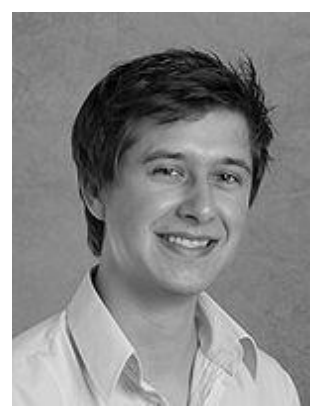

Jonas Lehner graduated in business engineering from Karlsruhe Institute of Technology (KIT). Currently he is a research associate at the Business Information Systems Chair of the Institute of Applied Informatics and Formal Description Methods (AIFB). His research areas are mobile business and secure cloud computing. He is a member of the German Informatics Society. 


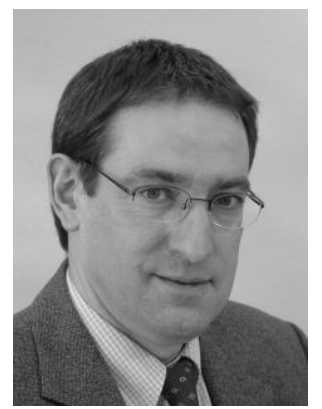

Andreas Oberweis is Professor for Applied Informatics at the Karlsruhe Institute of Technology (KIT). Since 2004 he is also Director at the Research Center for Information Technology (FZI) Karlsruhe. He received a Doctoral Degree in Informatics from University of Mannheim in 1990 and a Habilitation Degree in Applied Informatics from University of Karlsruhe in 1995. From 1995 to 2003 he was Professor for Information Systems Development at Goethe-University Frankfurt/Main. His research interests are in the field of business process engineering and information systems development. He is a member of the German Informatics Society.

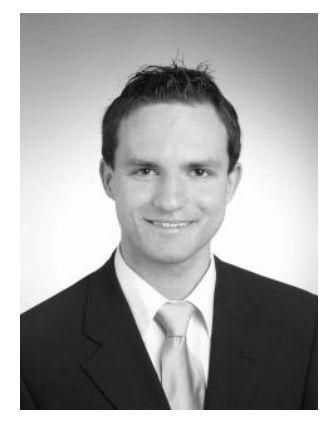

Andreas Schoknecht graduated in information management from Karlsruhe Institute of Technology (KIT). Currently he is a research associate at the Business Information Systems Chair of the Institute of Applied Informatics and Formal Description Methods (AIFB). His research topics are Semantic Business Process Management, process modeling and process mining.

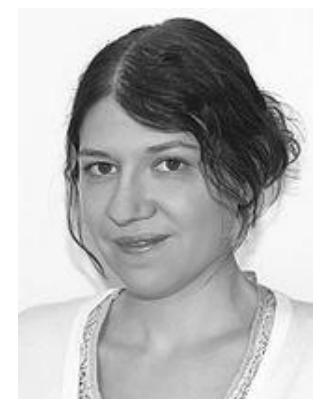

Meike Ullrich received her B.Sc. in Cognitive Science from University of Osnabrück and her M.Sc. in Applied Computer Science from University of Freiburg. Currently she is a research associate at the Business Information Systems Chair of the Institute of Applied Informatics and Formal Description Methods (AIFB). Her research interests include process mining, IT security and higher education modernization. She is a member of the German Informatics Society. 